\title{
Reductive dechlorination of 2-chlorophenol in a hydrogenotrophic, gas-permeable, silicone membrane bioreactor
}

\author{
Chao-Chien Chang ${ }^{\mathrm{a}, *}$, Szu-Kung Tseng ${ }^{\mathrm{a}}$, Chih-Cheng Chang ${ }^{\mathrm{b}}$, Chun-Ming Ho ${ }^{\mathrm{c}}$ \\ ${ }^{a}$ Graduate Institute of Environmental Engineering, National Taiwan University, 71 Chou Shan Rd., Taipei 106, Taiwan, ROC \\ ${ }^{\mathrm{b}}$ Department of Environmental Resources Management, Transworld Institute of Technology, Chia-Tong Campus: 1221, \\ Jen-Nang Rd., Douliu, Yunlin, Taiwan, ROC \\ ${ }^{c}$ Department of Environmental Engineering, Tung Nan Institute of Technology, 92 Wan-Fu Hamlet, Shen-Kun Village, Taipei, Taiwan, ROC \\ Received 13 November 2002; received in revised form 26 March 2003; accepted 20 April 2003
}

\begin{abstract}
A gas-permeable silicone membrane bioreactor was used to cultivate the biofilm under hydrogenotrophic condition for reductive dechlorination of 2-chlorophenol (2-CP). The anaerobic sludge obtained from a swine wastewater treatment plant was immobilized by polyvinyl alcohol (PVA) so as to form a biofilm on the surface of the silicone tube. After acclimating for about 4 months, the bioreactor showed a high dechlorinating performance. Under the condition of continuous feeding with $2-\mathrm{CP}$ at $25 \mathrm{mg} / \mathrm{l}$ and the hydraulic retention time of $15 \mathrm{~h}$, the 2-CP removal efficiency reached $92.8 \%$ (2-CP decay rate: $0.67 \mathrm{~g} / \mathrm{m}^{2} \mathrm{~d}$ of surface area of silicone tube). $\mathrm{H}_{2}$ was used as electron donor for dechlorinating 2-CP, and produced the dechlorinating intermediate, phenol. Both nitrate and sulfate played important roles in inhibiting 2-CP dechlorination through different biological mechanisms. Nitrate can be easily utilized as an electron acceptor by the biofilm, while sulfate cannot. Results of this study demonstrated that nitrate competed with 2-CP as the electron acceptor, while sulfate retarded the activity of hydrogen-dechlorinating bacteria and thus inhibited the 2-CP dechlorination.
\end{abstract}

(C) 2003 Elsevier Ltd. All rights reserved.

Keywords: Hydrogenotrophic; Chlorophenol; Phenol; Dechlorination; Biofilm; Bioreactor

\section{Introduction}

Chlorophenols (CPs) are widely used chemicals in industry to manufacture insecticides, herbicides, fungicides, biocides, and dye. They are also found in the effluent of the pulp and paper mill industry. These chemicals have been recognized as organic pollutants of air, groundwater, soil and sediments (Fetzner, 1998). Commonly, biological methods are used for the remediation of these pollutants. Chlorinated aromatic compounds can be biodegraded by either aerobic or anaerobic pathway. In aerobic pathway, the biodegradation of chlorinated aromatic compounds is more diverse since the ring cleavage may occur before dechlorination, thus forming more complex intermediates of varying toxicity. Contrarily, the anaerobic pathway in which chlorine substituents are replaced by hydrogen produces less-chlorinated compounds (Boyd et al., 1983;

\footnotetext{
${ }^{*}$ Corresponding author. Fax: +886-2-23637854.

E-mail address: grasschang@seed.net.tw (C.-C. Chang).
}

Boyd and Shelton, 1984; Reinecke and Knackmuss, 1988). This process is crucial because less chlorinated CPs are less toxic to the environment.

Several organic compounds can be used as the electron donor for reductive dechlorination, and thus stimulate the dechlorination of CPs (DeWeerd et al., 1991; Hendriksen et al., 1992; Holliger et al., 1999; Vallecillo et al., 1999). But the residual organic compounds were also problematic when used in groundwater remediation. For this reason, $\mathrm{H}_{2}$ was considered as an electron donor to take the place of the extra organic compounds. In fact, some bacteria have the ability to utilize $\mathrm{H}_{2}$ as electron donor for CP dechlorination. Amount them are Desulfomonile tiedjei, Desulfitobacterium chlororespirans and Desulfitobactreium dehalogenans (Holliger et al., 1999). $\mathrm{H}_{2}$ used as electron donor was also found by many researchers, to be used for reductive dechlorination of halobenzoate, tetrachloroethene (PCE), trichloroethene (TCE) and dichloroethene (DCE) (DeWeerd et al., 1991; Distefano et al., 1992; Ballapragada et al., 1997). However, the hydrogenotrophic bioreactor operated under 
continuous scheme for the dechlorination of CPs is rarely discussed in the literature. One of the main difficulties for cultivating hygrogenotrophic bacteria was the low water solubility of $\mathrm{H}_{2}$ (Chang et al., 1999). To alleviate this problem, a gas-permeable silicone membrane reactor was developed by our group to promote $\mathrm{H}_{2}$ utilization. The silicone tube offered a large surface area for $\mathrm{H}_{2}$ diffusion. The diffused $\mathrm{H}_{2}$ was directly utilized by the attached biofilm, and this would promote $\mathrm{H}_{2}$ utilization. This bioreactor was first adopted to cultivate Alcaligenes eutrophus biofilm supplied with $\mathrm{H}_{2}$ for nitrate removal and showed good performance (Ho et al., 2001). The present study further adopted this bioreactor to evaluate 2-CP dechlorination under hydrogenotrophic conditions.

\section{Methods}

\subsection{Synthetic wastewater}

The bioreactor was continuously fed with the synthetic wastewater. The synthetic wastewater contained $\mathrm{KH}_{2} \mathrm{PO}_{4}(1.0 \mathrm{~g} / \mathrm{l}), \mathrm{K}_{2} \mathrm{HPO}_{4}(1.0 \mathrm{~g} / \mathrm{l}), \mathrm{NaHCO}_{3}(1.0 \mathrm{~g} / \mathrm{l})$, $\mathrm{MgCl}_{2}(20 \mathrm{mg} / \mathrm{l}), \mathrm{NH}_{4} \mathrm{Cl}(30 \mathrm{mg} / \mathrm{l})$ and trace elements $(1 \mathrm{ml} / \mathrm{l})$. The trace elements solution comprised of $\mathrm{CaCl}_{2}$. $\mathrm{H}_{2} \mathrm{O}(7.3 \mathrm{~g} / \mathrm{l}), \mathrm{MnCl}_{2} \cdot 4 \mathrm{H}_{2} \mathrm{O}(2.5 \mathrm{~g} / \mathrm{l}), \mathrm{CoCl}_{2} \cdot 6 \mathrm{H}_{2} \mathrm{O}$ $(0.5 \mathrm{~g} / \mathrm{l}),\left(\mathrm{NH}_{4}\right)_{6} \mathrm{Mo}_{7} \mathrm{O}_{24} \cdot 4 \mathrm{H}_{2} \mathrm{O}(0.5 \mathrm{~g} / \mathrm{l}), \mathrm{FeCl}_{2} \cdot 4 \mathrm{H}_{2} \mathrm{O}$ $(2.0 \mathrm{~g} / \mathrm{l}), \mathrm{ZnCl}_{2}(1.0 \mathrm{~g} / \mathrm{l})$ and $\mathrm{CuCl}_{2}(0.1 \mathrm{~g} / \mathrm{l})$. The synthetic wastewater was deoxygenated by purging $\mathrm{N}_{2}$ for $5 \mathrm{~min}$, and then 2-CP (Nakarai Chemicals, LTD) was added in different specified concentrations. The synthetic wastewater was free from nitrate and sulfate to avoid the growth of denitrifying and sulfidogenic bacteria.

\subsection{Bioreactor}

The gas-permeable silicone membrane bioreactor was made of glass with an effective volume of $850 \mathrm{ml}$. Duplicate bioreactors were set and operated at the same conditions in this study. A silicone tube $(2.5 \mathrm{~mm}$ [i.d.] and $3.0 \mathrm{~mm}$ [o.d.] by $5.0 \mathrm{~m}$ long; Fuji system Co., Japan) was wound around the pillars in the reactor, as shown in Fig. 1. Anaerobic sludge from a swine wastewater treatment plant was immobilized on the tube wall to form a biofilm. The biofilm was immobilized by polyvinyl alcohol (PVA, Nacalai Tesque) and alginic acid (SIGMA), as described by Hsieh et al. (2002). A cylinder was used to supply pure $\mathrm{H}_{2}(20 \mathrm{ml} / \mathrm{min})$ to the lumen side of the silicone tube. The solution in the bioreactor was stirred by a magnetic stirrer bar to form a completely mixing reactor. In addition, the bioreactor was kept in a water bath to ensure the temperature at $25^{\circ} \mathrm{C}$. The $\mathrm{pH}$ value of the bioreactor was manually controlled by adding $1 \mathrm{M} \mathrm{HCl}$, or $1 \mathrm{M} \mathrm{NaOH}$ solution into the bioreactor.

\subsection{Batch experiments}

The batch experiments were conducted directly by two acclimated bioreactors to produce duplicate experimental results. Table 1 summarizes the initial conditions of these batch experiments. In the beginning of a batch experiment, the bioreactor was first emptied and added with $900 \mathrm{ml}$ of synthetic wastewater. A $10 \mathrm{ml}$

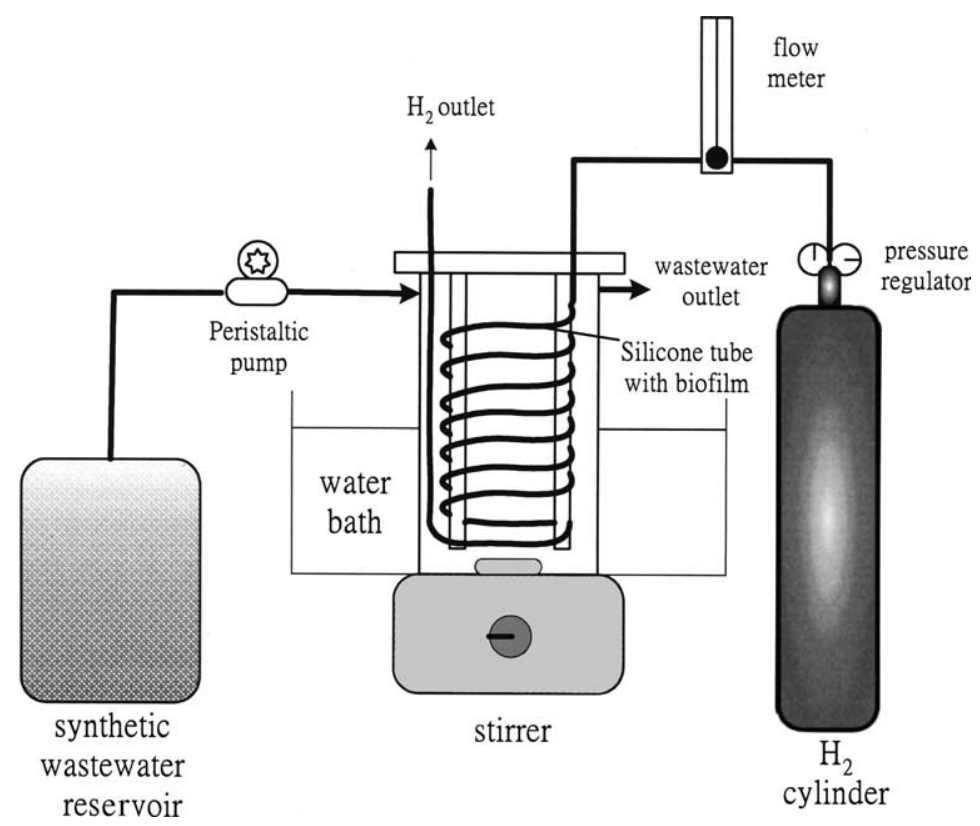

Fig. 1. Schematic diagram of the bioreactor. 
Table 1

Initial conditions for batch experiments

\begin{tabular}{|c|c|c|c|c|c|}
\hline Run no. & $\mathrm{pH}$ & 2-CP (mg/l) & $\begin{array}{l}\text { Supply } \mathrm{H}_{2} \\
\text { to the biofilm }\end{array}$ & $\begin{array}{l}\text { Nitrate addition } \\
(\mathrm{mg} \mathrm{N} / \mathrm{l})\end{array}$ & $\begin{array}{l}\text { Sulfate addition } \\
\left(\mathrm{mg} \mathrm{SO}_{4} / \mathrm{l}\right)\end{array}$ \\
\hline Run A & 5 & 50 & Yes & No & No \\
\hline Run B & 6 & 50 & Yes & No & No \\
\hline Run C & 7 & 50 & Yes & No & No \\
\hline Run D & 8 & 50 & Yes & No & No \\
\hline Run E & 9 & 50 & Yes & No & No \\
\hline Run F & $6.0-6.5$ & 25 & Yes & No & No \\
\hline Run $G$ & $6.0-6.5$ & 25 & No & No & No \\
\hline Run $\mathrm{H}$ & $6.0-6.5$ & 25 & Yes & 50 & No \\
\hline Run I & $6.0-6.5$ & 25 & Yes & No & 100 \\
\hline
\end{tabular}

sample was collected each time during a batch experiment period for analysis. The bioreactor was changed to the continuous-feeding mode for 2-3 days after each batch experiment for recovering the activity of the biofilm. The immobilized biofilm can minimize the perturbation to the bacteria, so the biofilm activity can soon recover after the batch experiments. All the batch experimental results are the average of duplicate experimental data.

\subsection{Analytical methods}

All samples were collected and filtered through a 0.22 $\mu \mathrm{m}$ PVDF syringe filter (Millipore). The 2-CP and phenol were determined by high-performance liquid chromatography (HPLC, equipped with Milipore Model 501 pump, Waters 486 detector and a Polaris 5u C18-A column). The mobile phase was a mixture of acetonitrile, distilled water and acetate in the proportion of 500/ $500 / 5.7(\mathrm{v} / \mathrm{v})$. The HPLC pump was controlled at the flow rate of $1.0 \mathrm{ml} / \mathrm{min}$, and the detector was set at 254 $\mathrm{nm}$. Nitrate, nitrite and sulfate were determined by ion chromatography (Dionex DX-120) with mobile phase of $1.7 / 1.8 \mathrm{mM} \mathrm{NaHCO} / \mathrm{Na}_{2} \mathrm{CO}_{3}$ at a flow rate of 1.25 $\mathrm{ml} / \mathrm{min}$. The total organic carbon (TOC) of the samples was determined by a TOC analyzer (O.I. Analytical Model 1010).

\section{Results and discussion}

\subsection{Start and acclimation of the bioreactor}

Experimental results of the bioreactor acclimation are listed in Table 2. All the data were collected and analyzed from one of the duplicated bioreactors. The total acclimation time was 110 days and subsequently divided into six periods. The first four periods (A-D) ran at the hydraulic retention time (HRT) of $20 \mathrm{~h}$ without controlling the $\mathrm{pH}$ value. The influent medium did not contain 2-CP in period A, so as to allow the hydrogen bacteria adapting to the environment. During period A, the $\mathrm{pH}$ value of the bioreactor increased to 7.7 , since the influent $\mathrm{pH}$ was controlled at $7.0 \pm 0.2$ (Table 2). Such an increase of $\mathrm{pH}$ value is probably due to the growth of hydrogen bacteria. 2-CP was first added into the influent at the concentration of $10 \mathrm{mg} / \mathrm{l}$ in period $\mathrm{B}$, so as to start acclimating the dechlorinating bacteria. Next, the influent 2-CP concentration was raised to $25 \mathrm{mg} / \mathrm{l}$ in period $\mathrm{C}$ and $50 \mathrm{mg} / \mathrm{l}$ in period $\mathrm{D}$, respectively. With the addition of 2-CP, the $\mathrm{pH}$ values of the bioreactor was still kept around 7.6-7.7 in periods B-D, that were almost the same within period A (Table 2). This result indicated that the degradation of 2-CP might not affect the $\mathrm{pH}$ value in this system. The 2-CP degradation rate increased with increasing the influent 2-CP concentrations in period $\mathrm{B}-\mathrm{D}$, showing that a higher influent 2-CP

Table 2

Conditions and analytical results of the bioreactor during acclimation

\begin{tabular}{|c|c|c|c|c|c|c|c|}
\hline \multirow[t]{2}{*}{ Period } & \multirow[t]{2}{*}{ Days } & \multirow[t]{2}{*}{ HRT (h) } & \multirow{2}{*}{$\begin{array}{l}\text { Influent } \\
\text { substrate } \\
2-\mathrm{CP}(\mathrm{mg} / \mathrm{l})\end{array}$} & \multicolumn{2}{|l|}{ Effluent } & \multirow{2}{*}{$\begin{array}{l}\text { 2-CP decay rate } \\
\left(\mathrm{g} / \mathrm{m}^{2} \mathrm{~d}\right)\end{array}$} & \multirow{2}{*}{$\begin{array}{l}\text { 2-CP removal } \\
\text { efficiency }(\%)\end{array}$} \\
\hline & & & & 2-CP (mg/l) & $\mathrm{pH}$ & & \\
\hline $\mathrm{A}$ & $1-10$ & 20 & 0 & 0 & $7.7 \pm 0.3$ & 0 & 0 \\
\hline B & $11-20$ & 20 & $9.6 \pm 0.5$ & $6.8 \pm 0.6$ & $7.7 \pm 0.1$ & 0.06 & 29.2 \\
\hline $\mathrm{C}$ & $21-30$ & 20 & $24.3 \pm 1.1$ & $16.0 \pm 0.3$ & $7.6 \pm 0.1$ & 0.18 & 34.2 \\
\hline $\mathrm{D}$ & $31-50$ & 20 & $48.8 \pm 1.4$ & $33.1 \pm 0.6$ & $7.7 \pm 0.2$ & 0.34 & 32.2 \\
\hline $\mathrm{E}$ & $51-86$ & ND & ND & ND & ND & ND & ND \\
\hline $\mathrm{F}$ & $87-110$ & 15 & $24.9 \pm 0.2$ & $1.8 \pm 0.3$ & $6.1 \pm 0.2$ & 0.67 & 92.8 \\
\hline
\end{tabular}

Period E: Batch experiments at different $\mathrm{pH}$ value.

ND: No data.

Data showed for 2-CP concentrations and $\mathrm{pH}$ values were the average $\pm \mathrm{SD}$ with three values in each period. 
concentration $(50 \mathrm{mg} / \mathrm{l})$ did not cause a harmful effect on the biofilm. However, the 2-CP removal efficiency was calculated to be $32.2 \%$ only, as the influent $2-\mathrm{CP}$ concentration was kept at $48.8 \mathrm{mg} / \mathrm{l}$ in period D (Table 2). It is considered that the $\mathrm{pH}$ value must be a key factor in affecting the 2-CP degradation in our system. Therefore, a series of batch experiments was conducted so as to obtain the optimal $\mathrm{pH}$ range of this bioreactor in period E.

In period $\mathrm{E}$, batch experiments at $\mathrm{pH} 5,6,7,8$ and 9 (see Table 1, Run A-E) were conducted to evaluate the $\mathrm{pH}$ effect on the 2-CP degradation. Each batch experiment was designated to run for four days. Then, the reactor switched to continuous-feeding mode for three days to recover the biofilm activity. All of the experimental results showed that the optimal $\mathrm{pH}$ value for dechlorinating 2-CP was in the range of $6-7$, and was greatly inhibited at $\mathrm{pH}$ either below 6 or higher than 7 . These results are in agreement with Chang et al. (1998), that the dechlorination of PCP was optimized at $\mathrm{pH} 7.0$, and completely inhibited at $\mathrm{pH} 6.0$ or 9.0 , indicating that $\mathrm{pH}$ affects dechlorination dramatically.

In period $\mathrm{F}$, the HRT and 2-CP concentration were changed to $15 \mathrm{~h}$ and $25 \mathrm{mg} / \mathrm{l}$, respectively, to shorten the stabilization time of the bioreactor. After an extended operation for one more month (period F) at $\mathrm{pH}$ 6.0-6.5, the 2-CP removal efficiency increased to $92.8 \%$ (2-CP decay rate: $0.67 \mathrm{~g} / \mathrm{m}^{2} \mathrm{~d}$ of surface area of silicone tube or $246 \mu \mathrm{mole} / \mathrm{ld}$ of bioreactor volume). This result indicated that the bioreactor was capable of remediating the 2-CP contaminated water without addition of external organic compounds as electron donors.

\subsection{Degradation of 2-chlorophenol}

The intermediate product of 2-CP dechlorination, phenol, was not detected under the continuous-feeding mode. The phenol was considered to be readily degraded as soon as it was derived from the 2-CP dechlorination. A further batch experiment was conducted to verify the dechlorination of 2-CP (Table 1, Run F). Experimental results showed that the 2-CP was completely degraded within $20 \mathrm{~h}$, and phenol produced during the 2-CP degradation (see Fig. 2). The phenol was further depleted in $26 \mathrm{~h}$. This indicated that the bioreactor contained phenol-degrading bacteria, which degraded the phenol and reduced the TOC values (Fig. 2). In other words, the bioreactor may exhibit a favorite ability to dechlorinate 2-CP to become a less toxic compound, phenol, and would also improve the water quality by reducing the TOC value.

Another batch experiment was conducted without the supply of $\mathrm{H}_{2}$ to illucidate the role of $\mathrm{H}_{2}$ (Table 1, Run G). In Run $\mathrm{G}$, the 2-CP degradation rate without supplying $\mathrm{H}_{2}$ was obviously much lower than that with $\mathrm{H}_{2}$ supplied. Phenol did not appear during the 2-CP degradation. The

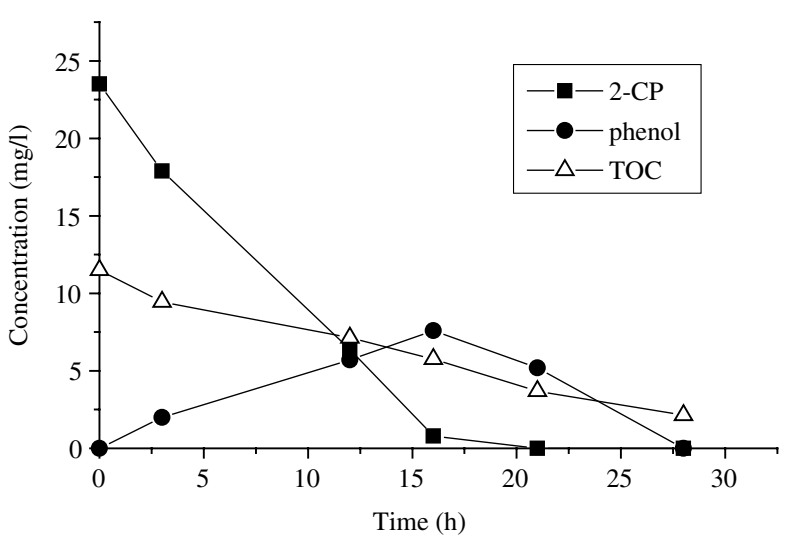

Fig. 2. Dechlorination of 2-CP under hydrogenotrophic condition in a batch experiment.

result showed that the 2-CP was not dechlorinated in deficient of $\mathrm{H}_{2}$, and another metabolic pathway might proceed under this condition. This indicates that the 2-CP dechlorination occurs only in the presence of an electron donor. Sanford and Tiedjei (1997) also proposed that the dechlorination activity could only sustained with the addition of an electron donor, such as acetate.

\subsection{Effects of different electron acceptors on dechlorina- tion}

Both nitrate and sulfate are well known as electron acceptors in biological reaction systems. They can inhibit reductive dechlorination (Madsen and Amand, 1991), though their inhibition behavior still remains much to be studied. In our study, a shock-loading test and batch experiments were adopted to explore the inhibiting mechanism for nitrate and sulfate. During the shockloading test, the bioreactor was operated with the continuous-feeding mode, under controlling the conditions similar to the period F in Table 2. Potassium nitrate was directly added to the bioreactor on the fourth day of this shock-loading test, so as to gain an initial nitrate concentration of $50 \mathrm{mg} \mathrm{N} / 1$ (Fig. 3). The effluent 2-CP concentration increased the next day after the addition of nitrate, causing the 2-CP removal efficiency to drop from $93 \%$ to $87 \%$. The $2-\mathrm{CP}$ dechlorination recovered in the following two days after the addition of nitrate, and in the same time, the effluent nitrate concentration became zero due to the dilution of continuous feeding. The sulfate shock-loading was started on the 19th day of this shock-loading test (Fig. 3). Potassium sulfate was added to the bioreactor to gain the sulfate concentration of 200 $\mathrm{mg} / \mathrm{l}$. Sulfate revealed a similar effect with nitrate on inhibiting 2-CP dechlorination. It also caused the effluent 2-CP concentration to increase, but it took three more days for recovery (Fig. 3). The inhibitory effect on 2-CP dechlorination in our system was supposed to be caused by nitrate and sulfate. Häggblom et al. (1993) had 


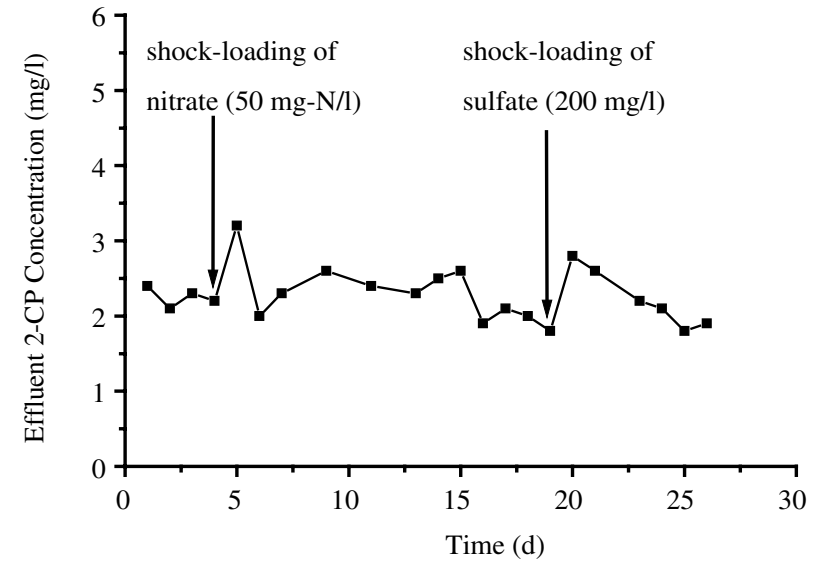

Fig. 3. Variation of effluent 2-CP concentration during the shockloading of nitrate and sulfate.

proposed that the 2-CP dechlorination only occurred under methanogenic condition, while sulfidogenic and denitrifying conditions did not. Their result is useful to explain the inhibitory effect on dechlorination in our system after the addition of nitrate and sulfate. However, the mechanism how nitrate or sulfate affects 2-CP dechlorination needs further study.

In order to further evaluate 2-CP dechlorination under nitrate and sulfate, respectively, two batch experiments were conducted (Table 1, Run $\mathrm{H}$ and I). The initial concentration of sulfate in Run I was $100 \mathrm{mg} / \mathrm{l}$, less than that in previous shock-loading test, to avoid serious inhibition. Fig. 4 presents the results that the 2-CP was completely degraded within $32 \mathrm{~h}$, with nitrate in the batch experiment. The degradation rate was quite low in comparison with the results of lacking nitrate in Fig. 2. Nitrate was rapidly consumed within $16 \mathrm{~h}$ and the denitrification was responsible for the depletion of nitrate. This was proved by the appearance of denitrification intermediate, nitrite, as the $\mathrm{pH}$ of the bioreactor increased. The dechlorination intermediate, phenol, was

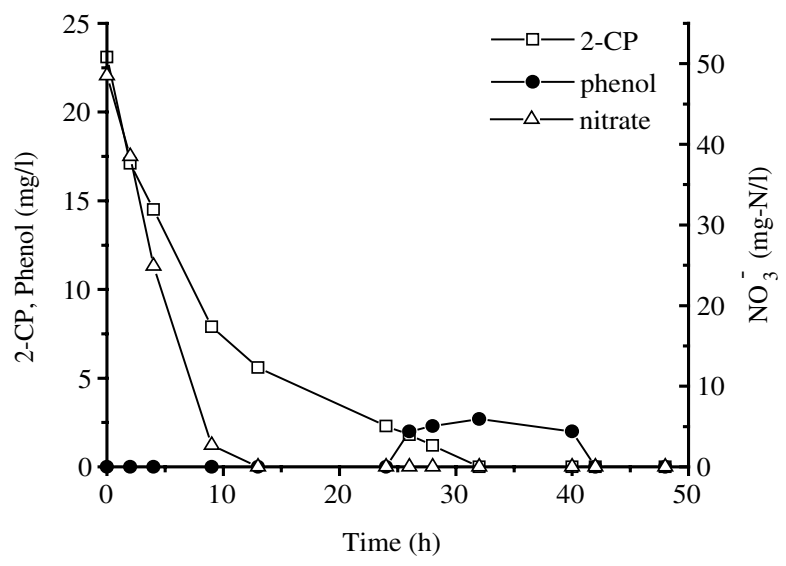

Fig. 4. The batch experiment of 2-CP degradation in the presence of nitrate.

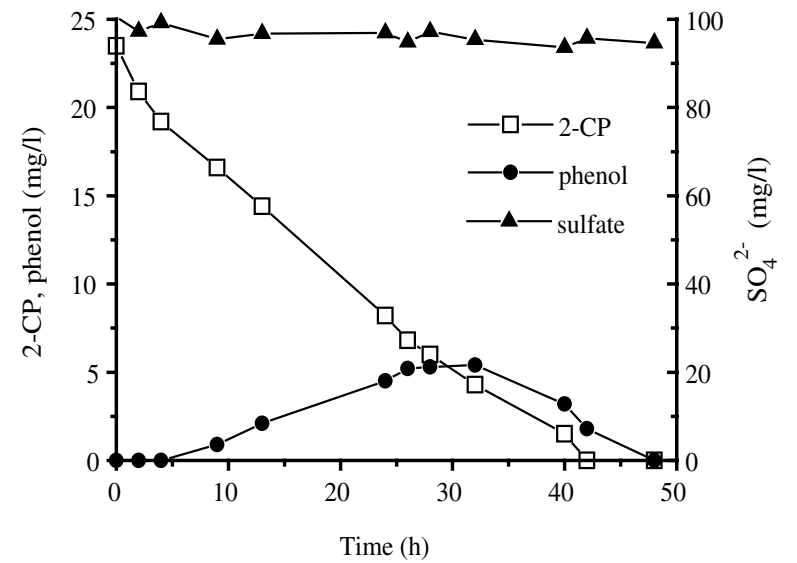

Fig. 5. The batch experiment of 2-CP degradation in the presence of sulfate.

not detected during the denitrifying period $(0-13 \mathrm{~h})$ (Fig. 4). Phenol was produced only after the depletion of nitrate. The above results showed that $2-\mathrm{CP}$ was not dechlorinated in the presence of nitrate, instead, 2-CP was used as a carbon source. This result is in agreement with the study of Bae et al. (2002). They proposed that 2-CP did not go through dechlorination but directly be utilized as carbon source under denitrifying condition. Our bioreactor also shows that nitrate is a better electron acceptor than 2-CP, if they are present in the solution concurrently. And this is the major cause that nitrate inhibited the 2-CP dechlorination in our study.

Fig. 5 shows the effect of sulfate on 2-CP dechlorination. The time for completely degrading 2-CP was 42 $\mathrm{h}$, indicating the lowest degradation rate. Unlike nitrate, sulfate was almost not consumed in our system. It indicated that sulfate was not utilized as electron acceptor, and thus, the 2-CP dechlorination continued to produce phenol in the presence of sulfate (Fig. 5). The results showed that the inhibition behavior of 2-CP dechlorination by sulfate differed from that by nitrate which competes with 2-CP as electron acceptor. Sulfate is, therefore, proposed to inhibit 2-CP dechlorination through retarding the activity of the hydrogen-dechlorinating bacteria.

\section{References}

Bae, H.S., Yamagishi, T., Suwa, Y., 2002. Evidence for degradation of 2-chlorophenol by enrichment cultures under denitrifying conditions. Microbiology 148, 221-227.

Ballapragada, B.S., Stensel, H.D., Puhakka, J.A., Ferguson, J.F., 1997. Effect of hydrogen on reductive dechlorination of chlorinated ethenes. Environ. Sci. Technol. 31, 1728-1734.

Boyd, S.A., Shelton, D.R., 1984. Anaerobic biodegradation of chlorophenols in fresh and acclimated sludge. Appl. Environ. Microbiol. 47, 272-277.

Boyd, S.A., Shelton, R.D., Berry, D., Tiedjei, J.M., 1983. Anaerobic biodegradation of phenolic compounds in digested sludge. Appl. Environ. Microbiol. 46, 50-54. 
Chang, B.V., Chiang, C.W., Yuan, S.Y., 1998. Dechlorination of pentachlorophenol in anaerobic sewage sludge. Chemosphere 36 (3), 537-545.

Chang, C.C., Tseng, S.K., Huang, H.K., 1999. Hydrogenotrophic denitrification with immobilized Alcaligenes eutrophus for drinking water treatment. Biores. Technol. 69, 53-58.

DeWeerd, K.A., Concannon, F., Suflita, J.M., 1991. Relationship between hydrogen consumption, dehalogenation, and the reduction of sulfur oxyanions by Desulfomonile tiedjei. Appl. Environ. Microbiol. 57, 1929-1934.

Distefano, T.D., Gossett, J.M., Zinder, S.H., 1992. Hydrogen as an electron donor for dechlorination of tetrachloroethene by an anaerobic mixed culture. Appl. Environ. Microbiol. 58, 36223629.

Fetzner, S., 1998. Bacterial dehalogenation. Appl. Microbiol. Biotechnol. 50, 633-657.

Häggblom, M.M., Rivera, M.D., Young, L.Y., 1993. Influence of alternative electron acceptors on the anaerobic biodegradability of chlorinated phenols and benzoic acids. Appl. Environ. Microbiol. $59,1162-1167$.

Hendriksen, H.V., Larsen, S., Ahring, B.K., 1992. Influence of a supplement carbon source on anaerobic dechlorination of penta- chlorophenol in granular sludge. Appl. Environ. Microbiol. 58, 365-370.

Ho, C.M., Tseng, S.K., Chang, Y.J., 2001. Autotrophic denitrofication via a novel membrane-attached biofilm reactor. Lett. Appl. Microbiol. 33, 201-205.

Holliger, C., Wohlfarth, G., Diekert, G., 1999. Reductive dechlorination in the energy metabolism of anaerobic bacteria. FEMS Microbiol. Rev. 22, 383-398.

Hsieh, Y.L., Tseng, S.K., Chang, Y.J., 2002. Nitrification using polyvinyl alcohol-immobilized nitrifying biofilm on an $\mathrm{O}_{2}$-enriching membrane. Biotech. Lett. 24, 315-319.

Madsen, T., Amand, J., 1991. Effect of sulfuroxy anions on degradation of pentachlorophenols by a methanogenic enrichment culture. Appl. Environ. Microbiol. 57, 2453-2458.

Reinecke, W., Knackmuss, H.J., 1988. Microbial degradation of haloaromatics. Ann. Rev. Microbiol. 42, 263-287.

Sanford, R.A., Tiedjei, J.M., 1997. Chlorophenol dechlorination and subsequent degradation in denitrifying microcosms fed low concentrations of nitrate. Biodegradation 7, 425-434.

Vallecillo, A., Garcia-Encina, P.A., Peña, M., 1999. Anaerobic biodegradability and toxicity of chlorophenols. Water Sci. Technol. 40, 161-168. 